Revista de

Contabilidade e

Organizações
DOI: http://dx.doi.org/10.11606/rco.v8i22.55608
Journal of

Accounting and

Organizations

www.rco.usp.br

\title{
A efetividade dos institutos supremos de auditoria e dos legislativos na transparência fiscal
}

Robson Zuccolotto ${ }^{\mathrm{a}}$, Marco Antônio Carvalho Teixeira ${ }^{\mathrm{b}}$

${ }^{a}$ Faculdade de Economia, Administração e Contabilidade da Universidade de São Paulo

${ }^{b}$ Pontificia Universidade Católica de São Paulo

\section{Informações do Artigo}

\section{Histórico do Artigo}

Recebido: 15 de maio de 2013

Aceito: 21 de novembro de 2014

Palavras chave:

Transparência

Accountability

Democracia

Corrupção

Sociedade Civil

\begin{abstract}
Resumo
Este trabalho teve por objetivo identificar a efetividade dos Institutos Supremos de Auditoria (SAIs) e dos Poderes Legislativos na transparência fiscal dos países. Além disso, buscando testar empiricamente a teoria, foi analisada, como a transparência melhora a accountability e como elas, em conjunto (transparência e accountability) se relacionam com o nível de democracia de um país e com a percepção de corrupção. Para realizar os testes propostos foram utilizados modelos de regressão linear múltipla pelo método dos mínimos quadrados ordinários e os dados foram obtidos de relatórios oficiais de transparência, democracia e corrupção como Open Budget Partnership, Transparência Internacional, Economist Inteligent Unit's Index e Index Mundi. Os resultados demonstram que países onde os Poderes Legislativos e as SAIs possuem mais independência, constitucionalmente determinada, existe também, maior transparência orçamentária. Contatou-se, ainda, que países mais transparentes possuem mais e melhores mecanismos de accountability e, consequentemente, maior nível de democracia e menos corrupção, evidenciando a importância da transparência no processo de consolidação democrática.
\end{abstract}

Copyright $(\underset{0}{ } 2014$ FEA-RP/USP. Todos os direitos reservados

\section{INTRODUÇÃO}

Nem a palavra nem muitos dos significados da transparência, na forma como são discutidos na atualidade, são uma invenção do século XX. Conforme já destacado, a transparência figurava em muitas das regras de administração do século XIX muito antes de ganhar proeminência nas últimas duas décadas do século $\mathrm{XX}$. Porém, somente na última década do século XX esse conceito ganhou expressão social, passando a integrar a agenda governamental (HOOD, 2006; BESSETE, 2001). Uma das principais razões que impulsionaram as discussões e aumento de iniciativas em torno de uma maior transparência na gestão pública foi a preocupação de que, quando o histórico das opções políticas não é conhecido, o eleitorado é incapaz de "punir" os políticos que se envolvem em corrupção e outras formas de conduta ilegal (FOX, 2007).

Autor Correspondente: Tel + 5531 3899-2886

E-mail : zrobson@ufv.br (R. Zuccolotto); marco.teixeira@fgv.br (M. A. C. Teixeira)

UFV - Centro de Ciências Humanas Letras e Artes - Departamento de Administração - Av. P. H. Rolfs, s/n - Campus Universitário - 36570-000 Viçosa - MG, Brasil
Nesse sentido, partindo-se de uma perspectiva política, a transparência governamental tem sido vista como parte integrante das tentativas de melhorar a governança no setor público desde o inicio dos anos 1990 e, de forma breve, pode ser definida como o grau com o qual os cidadãos, a mídia e os mercados financeiros podem observar as estratégias dos governos, suas ações e resultados (ALT e LASSEN, ROSE, 2006).

Umas das formas socialmente legitimadas de comunicação desses objetivos, metas e resultados são os orçamentos e relatórios contábeis dos governos, também conhecido por transparência fiscal (orçamentária). Diversos estudiosos de transparência (LORD, 2000; ALT; LASSEN, 2006; HALLERBERG; WOLFF, 2008; HEPPKE-FALK; WOLFF, 2008; BERNOTH; WOLFF, 2008) destacam que elaborar orçamentos e balanços públicos mais transparentes e com mecanismos de fiscalização adequados possibilita a priorização de políticas, aumenta a credibilidade dos governos, limita a corrupção e o gasto desnecessário, melhora a liquidez e facilita o acesso aos mercados financeiros.

Por consequência, a transparência orçamentária tem se tornado tema central nos debates sobre desenvolvimento internacional, sendo utilizada em temas relativos à cooperação internacional e solução 
de conflitos (PALLAS; URPELAINEN, 2012), monitoramento de compromissos internacionais, sejam comerciais ou financeiros, bem como monitoramento dos recursos recebidos a título de ajuda pelos países em desenvolvimento ou pelos países com crises financeiras (CHANDY; KHARAS, 2011), redução da corrupção e melhora do desempenho econômico (GRIGORESCU, 2007; PARK; BLENKINSOPP, 2011; CORREA; SPINELLI, 2011).

Przeworski (2010) escreve, ainda, que a transparência permite que os cidadãos saibam se os governos estão ou não estão atuando na defesa dos interesses públicos e, desta forma, possam aplicar-lhes as sanções apropriadas, de tal modo que os políticos que atuarem em favor dos interesses dos cidadãos sejam reeleitos e os que não o tenham feito percam as eleições. Em outras palavras, permite que os governos sejam responsabilizados, ao menos politicamente, pelos seus atos ${ }^{1}$. Todavia, em um ambiente democrático, com instituições consolidadas e fortes, a responsabilização (accountability) não deve existir apenas na esfera política e, nesse sentido, Schedler (1999) estabelece três questões identificadas como necessárias para sua eficácia: informação, justificação e punição. As duas primeiras (informação e justificação) remetem-nos ao que o autor denomina de answerability, isto é, a obrigação dos detentores de mandatos públicos informarem, explicarem e responderem pelos seus atos; enquanto a última (punição) diz respeito à capacidade de enforcement, ou seja, a capacidade das agências de impor sanções e perda de poder para aqueles que violarem os deveres públicos.

Corroborando as afirmações anteriores, Meijer (2009) destaca que a transparência é suposto para melhorar os governos em todo o mundo, reduzindo a corrupção e aumentando a accountability para os cidadãos. Adicionalmente, pode se destacar que a transparência é uma ferramenta fundamental para os governos aumentarem sua credibilidade, melhorarem as relações internacionais, o acesso a mercados e crédito, reduzirem a corrupção, entre outros (BERTOT ET AL., 2009; CUILLIER; PIOTROWSKI, 2009; MULGAN, 2007; RELYEA, 2009; SHULER ET AL., 2010).

Todavia, Kaufman (2005) destaca que sua implementação e desenvolvimento dependem de instituições orçamentárias ${ }^{2}$ eficientes. Desta forma, no processo orçamentário, duas instituições assumem papel central no desenvolvimento e institucionalização da transparência, sendo eles: os Supreme Audit Institutions e os poderes legislativos. Corroborando essa afirmação, o IBP (2010) destaca a importância da independência dos Institutos Supremos de Auditoria (SAIs) ${ }^{3}$ e dos poderes

\footnotetext{
1 Da citação de Przeworski (2010) deve-se atentar ao fato de que

se trata de uma possibilidade e não de uma certeza.

2 Hagen (2007) destaca que instituições orçamentárias são todas as regras e regulamentos segundo a qual os orçamentos são elaborados, aprovados e implementados.

3 Sigla correspondente ao termo em inglês Supreme Audit Institution. No Brasil o órgão correspondente é o Tribunal de Contas da União (TCU). Sobre o desenvolvimento institucional e atribuições constitucionais do TCU ver Teixeira (2010).
}

legislativos para aprovar orçamentos e emendas ao mesmo e, consequentemente, aumentar a transparência fiscal dos países contribuindo, desta forma, para a redução da corrupção.

Assim, mesmo que muitos estudos tenham sido realizados abordando a temática transparência e, mais especificamente, a transparência fiscal, poucos se limitaram a conhecer as causas da transparência fiscal e, salvo melhor análise, nenhum se dedicou a conhecer a efetividade das Instituições democráticas para o desenvolvimento da transparência e combate à corrupção. Por isso, em função de todas as argumentações apresentadas, esse trabalho buscará responder ao seguinte questionamento: Qual a efetividade dos organismos de controle (SAI) e fiscalização (Legislativo) na melhoria da transparência e, consequentemente, na redução da corrupção no setor público?

De forma geral, objetiva-se, a partir do problema proposto, identificar a importância da independência do poder legislativo e das Instituições Supremas de Auditoria na transparência dos países e, secundariamente: i) identificar em que intensidade a transparência influencia os mecanismos de accountability; ii) identificar a intensidade na qual a transparência e a accountability influenciam a percepção de corrupção e, iii) identificar em que intensidade a transparência e a accountability influenciam o nível de democracia dos países.

O trabalho está estruturado da seguinte forma: na seção dois apresentam-se os conceitos de transparência, bem como as pesquisas que fundamentam esse trabalho. $\mathrm{Na}$ seção três apresentam-se os métodos utilizados para coleta e análise de dados, enquanto a seção quatro apresenta os resultados da pesquisa e a seção cinco as considerações finais deste trabalho.

\section{REFERENCIAL TEÓRICO}

\subsection{A transparência e sua importância}

Conforme destaca Grigorescu (2003), a consciência sobre a importância do tema transparência e do seu potencial poder explicativo tem ganhado relevância entre pesquisadores de diversos campos do conhecimento e que, por causa da variedade de interesses envolvendo o fluxo de informações, o conceito de transparência não foi monopolizado por nenhuma área de estudo, podendo ser encontrado em estudos sobre conflitos internacionais, organizações internacionais, ambiente político, política monetária, comércio, corrupção, teoria democrática, gestão pública etc.

Independentemente da área estudada, o debate sobre transparência tem se tornado um tema central na agenda de quase todas as organizações, sejam elas públicas ou privadas, grandes ou pequenas (HOOD, 2006, p. 3) sugerindo que a mesma atingiu uma significância "quase 
religiosa" no debate sobre governança e desempenho institucional. Ball (2009) sugere que o tema transparência está começando a subsumir a accountability no discurso publico sobre boa governança. Essa demanda acentuada por transparência está baseada em vários fatores. $\mathrm{O}$ primeiro fator é que a transparência é uma das reivindicações morais fundamental nas sociedades democráticas, onde o direito do povo de ter acesso às informações é amplamente aceito (PASQUIER; VILLENEUVE, 2007). O segundo fator é que a transparência é uma medida prática para reduzir a corrupção, agindo como um elemento de dissuasão do comportamento corrupto, ou seja, dissuadindo os servidores públicos de abusar de seus cargos para atingir interesses privados, uma vez que promove a constante vigilância dos cidadãos (FLORINI, 2007). Corroborando com as afirmações anteriores, O'Neill (2006) observa que a transparência pode, também, servir como uma estratégia para deter a corrupção e corrigir baixa performance. $\mathrm{O}$ terceiro fator é que a transparência tem um efeito positivo na confiança e na accountability (HEALD, 2006). De acordo com Holzner e Holzner (2006, p. 114), "transparência está associada à prestação de contas e a accountability", uma vez que permite ao cidadão monitorar a qualidade do serviço público e, como consequência, encoraja os governos a melhorarem a qualidade dos gostos e dos serviços prestados aos cidadãos.

De forma ampla, conforme destacado por Fox (2007), uma das principais razões que impulsionaram as discussões e aumento de iniciativas em torno de uma maior transparência na gestão pública foi a preocupação de que, quando o histórico das opções políticas não é conhecido, o eleitorado é incapaz de "punir" os políticos que se envolvem em corrupção e outras formas de conduta ilegal. Adicionalmente, Speck (2002) relata que a transparência é importante por que i) é a base para a prática da accountability ${ }^{4}$; ii) é uma ferramenta para combater a má gestão bem como a corrupção; iii) promove a confiança pública; e $i v$ ) possibilita o acesso do cidadão às informações da Administração Pública.

\subsection{Interfaces conceituais entre transparência, democracia, accountability e percepção da corrupção}

Mesmo que o conceito de transparência seja cada vez mais encontrado na literatura acadêmica, seu significado ainda permanece escorregadio e, em parte, isso se deve ao fato desse conceito ser usado em diferentes aspectos relacionados ao fluxo das informações. Na literatura sobre conflitos entre países, um país é transparente se o outro país consegue obter informações sobre as preferências da sociedade e seu respectivo apoio às ações do governo.

4 Accountability aqui entendida como a obrigação daquele que administra os recursos públicos de prestação de contas de sua gestão e da possibilidade de ser responsabilizado pelo que faz. Um entendimento mais adequado sobre o conceito de accountability, o sentido dessa palavra e como essa questão desafia o Brasil pode ser verificado em Campos (1990) e Pinho e Sacramento (2009).
Todavia, na literatura sobre regimes ${ }^{5}$ internacionais, transparência refere-se às informações que os países oferecem aos organismos internacionais e; em estudos sobre corrupção, transparência se refere à existência de informação acerca de práticas de corrupção em um país e de como são acionados o conjunto de medidas existentes para combatê-la. Na literatura de Ciência Política, o conceito de transparência está associado à divulgação de informações por parte dos governos para atores internos e externos (GRIGORESCU, 2003).

Piotrowski, (2007), destaca que transparência é genericamente definida como fluxo de informações aberto à sociedade e que a literatura sobre transparência na relação entre governantes e cidadãos tem enfatizado cada vez mais a importância dessa abertura. Complementa seu pensamento afirmando que transparência governamental equivale a abrir o governo.

Oliver (2004), por sua vez, argumenta que transparência na organização não se refere apenas ao que é comunicado externamente, mas, sobretudo, ao que é certo comunicar, e introduz o conceito de "new transparency" para descrever a tendência atual na qual as organizações são fortemente demandadas a divulgar informações. Destaca ainda que no passado vários governos proviam informações de forma passiva, ou seja, apenas quando eram requeridas. Atualmente, no entanto, a exigência para que os governos divulguem, de forma ativa, mais e melhores informações aumentaram significativamente.

Aplicado ao campo da Administração Pública, Birkinshaw (2006, p.189) diz que a "transparência pode ser entendida como a gestão dos assuntos públicos para o público" e, West (2004) completa relatando que transparência se refere ao nível de abertura das contas públicas e das decisões governamentais aos cidadãos. Além disso, Coglianese (2009) sugere que transparência pode auxiliar o governo de duas maneiras: i) promover o diálogo entre os gestores públicos e os cidadãos antes de as decisões serem tomadas e; ii) prevenir conflitos de interesses por parte de servidores por meio de uma maior e mais profunda vigilância por parte dos cidadãos.

Quanto a sua definição, o clássico conceito de Kopits e Graig (1998, p.1), destaca que transparência fiscal pode ser definida como,

abertura para o público em geral sobre a estrutura e funções de governo, as intenções da política fiscal, as contas do setor público e as projeções econômicas. Envolve pronto acesso a informação confiável, abrangente, oportuna, compreensível e internacionalmente comparáveis sobre as atividades do governo [...] para que o eleitorado e os mercados financeiros possam avaliar com precisão a posição financeira do governo e os verdadeiros custos e benefícios das atividades do mesmo, incluindo as implicações sociais e 5 Um regime, conforme definido por Krasner (1983) é um conjunto explícito ou implícito de "princípios, normas, regras e procedimentos de tomada de decisão em torno da qual as expectativas dos atores sociais convergem em uma determinada área temática." Esta definição é intencionalmente ampla, e abrange as interações humanas que vão desde as organizações formais (ONU, FMI, etc.) até grupos informais (associações não formalizadas). 
econômicas presentes e futuras ${ }^{6}$.

Dado o conceito anterior, Colecchia e Schreyer (2002) exemplificam que um processo orçamentário transparente é aquele que fornece todas as informações sobre a política fiscal dos governos e que o fazem de forma simples, com poucas complexidades contábeis e demonstrações compreensíveis. Exemplificam, por fim, que orçamentos que são acessíveis ao público e aos formuladores de políticas públicas, bem como aqueles que apresentam informações consolidadas e compreensíveis são transparentes.

Destaca-se, no entanto, que nem sempre a transparência esteve presente nos modelos gerenciais dos governos, surgindo apenas a partir da implantação do modelo denominado Public Service Orientation (PSO), que, além da equidade, introduziu a accountability (responsabilização dos gestores), a qual, para sua efetivação, deverá ser precedida pela transparência (PHILIPPS; STEWART, 2008). Essa mudança dos objetivos da efetividade/qualidade para accountability/ equidade, conforme destacado por Matias Pereira (2002), foi motivada pela forma de enfocar o publico alvo, atribuindo-lhes, além de direitos, deveres para com o Estado e para com os outros cidadãos. Além disso, o autor destaca que outro item importante do PSO é que se baseia na descentralização dos serviços públicos permitindo, desta forma, a introdução da accountability bem como a participação do cidadão na definição de políticas públicas.

Como consequência da descentralização do Estado, Silva (2001) destaca que a instituição do Estado carrega, implicitamente, um conflito distributivo potencial entre os agentes privados que tentam se fazer representar politicamente por meio de grupos de pressão. Essas práticas podem ser acompanhadas pela defesa dos interesses privados dos próprios agentes públicos e, por isso, torna-se necessário estabelecer um sistema legal capaz de minimizar a possibilidade de apropriação indevida dos recursos públicos decorrentes do conflito distributivo entre todos os agentes da sociedade. Matias Pereira (2002) complementa afirmando que fica evidenciado, então, que a busca da transparência nos países democráticos exige a criação de instituições de controle, direito e garantia do bem público. Para tanto, a disponibilização de informações por meio de uma política efetiva de transparência pública dos atos governamentais torna-se indispensável para que os cidadãos se tornem aliados das instituições de controle na função de zelar pela integridade da gestão dos recursos públicos.

Entretanto, transparência pública não se realiza na sua plenitude se ela estiver dissociada de processos democráticos. Assim, como verificado na definição de

6 openness toward the public at large about government structure and functions, fiscal policy intentions, public sector accounts, and projections. It involves ready access to reliable, comprehensive, timely, understandable, and internationally comparable information on government activities . . . so that the electorate and financial markets can accurately assess the government's financial position and the true costs and benefits of government activities, including their present and future economic and social implications. transparência, o termo democracia também é carregado de controvérsias e escorregadio (SARTORI, 1994). Entretanto, trazendo a discussão para o âmbito das relações políticas, Loureiro et all (2010) constroem três tipos ideais que funcionam como princípios orientadores da existência de um regime democrático, algo indispensável para que se efetive o princípio da transparência pública: 1) o governo deve emanar da vontade popular pelo mecanismo do voto livre, o que se torna a principal fonte da soberania e que confere legitimidade ao governante e seus atos; 2) os governantes devem prestar contas ao povo, justificando seus atos e omissões durante o exercício do poder, o que possibilita aos cidadãos ter acesso a informações tanto para cobrar a responsabilização das autoridades públicas como para, na hora do voto, decidir se confere ou não ao mandatário o direito de permanecer no cargo; e 3) o Estado e a autoridade estatal devem ser regidos por regras que $a$ priori delimitem seu campo de atuação e possibilitem aos cidadãos o direito de queixa toda vez que ele se sentir ameaçado em seus direitos pela ação de tais autoridades.

Afinal, no que mais transparência pública depende da existência de democracia? A possibilidade do contraditório é indispensável para a consistência das informações disponibilizadas à sociedade. Um dado governamental deve ser questionado e desconstruído até o limite de se confirmar ou não a sua veracidade. Situações dessa natureza são possíveis, apenas, em regimes democráticos. Nas situações em que as fontes de informações não podem ser questionadas e contraditas, a transparência não cumpre adequadamente o seu papel de empoderar a sociedade e seus representantes. A ausência, ou baixa qualidade das informações, enfraquece as instituições que formam o sistema de accountability porque os cidadãos estão desprovidos de informações necessárias e compreensíveis que possibilitem demandar a defesa de seus interesses cobrando responsabilidade das autoridades públicas. Vale lembrar que Prado, Ribeiro e Diniz (2012, p. 19) afirmam que a dimensão conceitual de accountability "atinge não somente a prestação de contas e a publicidade das ações dos governos, mas, também, a existência de mecanismos institucionais de controle da administração pública que possam gerar incentivos e sanções".

A accountability depende fundamentalmente da existência de transparência dos atos dos governantes. A qualidade e consistência da transparência e a existência de mecanismos de queixa e responsabilização são inerentes ao regime democrático. Se como afirma Thompson (2002, p. 97) corrupção pode ser entendida como "perversão ou falta de integridade no desempenho de obrigações públicas através de subornos ou favores", a percepção da sociedade sobre práticas de corrupção tende a aumentar em ambiente de liberdade política (democracia) onde a competição pelo poder e disponibilização de informações exige maior publicidade dos negócios públicos. Como disse Ribeiro (2000), a revelação sobre esquemas de corrupção acaba se configurando em uma virtude do ambiente democrático e não em um problema da democracia como muitas vezes se faz pensar. 
A criação de um ambiente favorável para minimizar práticas lesivas ao patrimônio público com a melhoria do arcabouço legal, o fortalecimento das instituições e a criação de canais de diálogo entre a sociedade e as instituições de controle só é possível se transparência, accountability e democracia estiverem simultaneamente articulados. Se a existência de democracia é condição necessária para que se acionem instrumentos eficientes de transparência e accountability, o aperfeiçoamento e consolidação da democracia são resultados inevitáveis quando se vivencia uma sociedade com alto grau de transparência e onde as instituições de controle se tornam mecanismos eficientes de preservação da integridade pública. A seção seguinte discutirá a importância das instituições para aumentar a transparência e accountability nos países.

\subsection{A importância das instituições orçamentárias no processo de transparência dos países}

Instituições orçamentárias, de acordo com Hagen (2007) são todas as regras e princípios, formais e informais, segundo os quais os orçamentos são elaborados, aprovados e implementados. Além disso, esse conjunto de regras divide o processo em diferentes fases, determinando quem faz e o que faz em cada fase, além de regular o fluxo de informação entre os vários atores desse processo. Nesse sentido, o autor destaca que as instituições moldam os resultados do processo de tomada de decisão orçamentária que governam. Destaca-se, ainda, que essas instituições variam entre os países e, em menor medida, ao longo do tempo, e, desta forma, podem ser usadas para explicar as variações da política fiscal e, por consequência, da transparência e da accountability entre os países. Além disso, conforme destacam Hall e Taylor (2003), a escolha de diferentes instituições pode ser função de variáveis sociais, políticas e históricas que podem influenciar tanto a escolha institucional como o resultado fiscal.

Desta forma, uma vez que as instituições decorrem de um processo sócio-histórico-cultural, sua mudança ocorre com pouca frequência, podendo ser considerada pré-determinada, ao menos a curto e médio prazo. Em outras palavras, uma vez que é caro e complexo mudar as instituições existentes, essas deveriam apresentar desempenho muito insatisfatório para que valesse a pena alterá-las e, como resultado, observa-se uma forte predisposição na manutenção do status quo nas reformas institucionais.

De forma geral pode-se distinguir entre dois tipos de instituições: leis que prescrevem metas orçamentárias e as regras processuais. Com relação às leis que estabelecem metas orçamentárias, essas estão normalmente associadas a teorias macroeconômicas e, nesse trabalho não serão amplamente debatidas. No que se refere às regras processuais, pode-se identificar três fases no processo orçamentário: $i$ ) a formulação da proposta de orçamento dentro do executivo; ii) a apresentação e aprovação do orçamento no legislativo e; iii) a execução do orçamento pelos governantes (ALT; LASSEN, 2006).

Destaca-se, no entanto, que durante muitos anos a elaboração dos orçamentos era atividade exclusiva do poder executivo que, normalmente, o delegava ao ministério das finanças ou do tesouro. Nesse processo além do fato de que poucas informações eram divulgadas sobre o orçamento, nada se conhecia a respeito de como as prioridades eram definidas. No entanto, o surgimento da nova administração pública gerencial, com ênfase na maior abertura do processo orçamentário e a necessidade de instituições de supervisão fortes, levou à criação de um sistema orçamentário no qual três órgãos estatais passam a ter papel formal no processo orçamentário; o executivo, o legislativo e as Instituições Supremas de Auditoria (SANTISO, 2004).

A razão da existência dos três organismos estatais, descritos anteriormente, nos modernos sistemas de finanças públicas é proporcionar o controle efetivo das contas e, dessa forma, garantir que os fundos recolhidos serão gastos de forma que reflita as prioridades nacionais e promova o desenvolvimento (IBP, 2010). Nesse sentido, o papel do executivo é propor o orçamento; ao legislativo, na condição de representante do povo, cabe o papel de aperfeiçoá-lo, discuti-lo, emendá-lo, aproválo, veta-lo e monitorar sua execução pelos governos, enquanto às instituições supremas de auditoria compete fiscalizar a execução orçamentária e auxiliar o legislativo nesse papel.

Adicionalmente, no que se refere às SAIs, essas instituições funcionam como agências que irão informar ao legislativo e ajudá-lo na fiscalização da execução orçamentária e, por isso, verificam se as receitas estão sendo arrecadadas e se os gastos realizados pelo executivo são consistentes tanto em relação ao orçamento aprovado, como no que se refere aos regulamentos da legislação financeira. Geralmente, as SAIs apresentam seus relatórios de auditoria aos poderes legislativos que, por sua vez, organizam audiências para discutir as conclusões contidas nos relatórios de auditoria e, com base nessas audiências, fazer recomendações de medidas corretivas ao poder executivo. Em seguida, o legislativo avalia se o executivo cumpriu as recomendações exigidas fechando-se, desta forma, o ciclo da accountability (IBP, 2010).

A fim de realizar a supervisão eficaz dos orçamentos os legislativos e as SAIs necessitam de autoridade legal, de preferência constitucional, especificando as suas funções e a natureza de suas relações com o executivo. Desta forma, tanto os legislativos quanto as SAIs tendem a ser mais eficazes no desempenho de seus papeis quando forem providos, constitucionalmente, de poderes legais, capacidade de investigação e informações completas sobre as finanças públicas.

Todavia, muitos países ainda apresentam legislativos e SAIs com baixa independência, sem poderes constitucionais definidos, baixa capacidade de investigação e, consequentemente, poucas informações sobre os gastos e arrecadações de seus governos. Por 
consequência, acredita-se que o nível de transparência de países onde essas instituições são frágeis seja menor, comprometendo os instrumentos de accountability e, consequentemente o nível de democracia. Uma vez que o objetivo deste trabalho é identificar como a independência das instituições de monitoramento e controle do executivo auxilia no processo de transparência, as principais hipóteses desse trabalho são:

$\mathrm{H}_{0}$ : Países com instituições de monitoramento e controle mais independentes divulgam mais informações fiscais e apresentam orçamentos mais transparentes.

$\mathrm{H}_{1}$ : Países que divulgam mais e melhores informações orçamentárias possuem mais e melhores mecanismos de accountability.

$\mathrm{H}_{2}$ : Países mais transparentes e com melhores mecanismos de accountability possuem maior nível de democracia.

$\mathrm{H}_{3}$ : Países mais transparentes e com melhores mecanismos de accountability possuem menores índices de percepção de corrupção.

Desta forma, para que se pudesse testar as hipóteses apresentadas e, consequentemente, confirmar a teoria existente, descreve-se, a seguir, o caminho metodológico utilizado nesse trabalho.

\section{METODOLOGIA}

Quanto aos seus objetivos, essa pesquisa pode ser classificada como descritiva, uma vez que busca estabelecer relações entre as variáveis: transparência, accountability e democracia. Quanto aos procedimentos técnicos, a pesquisa classifica-se em documental, visto que se utilizou de relatórios de organismos oficiais, como o Open Budget Partnership, The Economist, Transparência Internacional e Index Mund e, experimental, uma vez que foi determinado um objeto de estudo, selecionadas as variáveis que seriam capazes de influenciá-lo e definidas as formas de controle e de observação dos efeitos que a variável produz no objeto.

No que se refere à coleta de dados, utilizou-se uma amostra de 94 países, agrupados pelas seguintes regiões geográficas: Leste da Ásia e Pacífico, Europa Oriental e Ásia Central, América Latina e Caribe, Meio Leste e Norte da África, Sul da Ásia, África Subsaariana. Uma vez que não existiam informações relativas à transparência disponíveis para todos os países, a amostra consistiu dos mesmos países do Open Budget Survey $2010^{7}$. Destaca-se, no entanto, que os países São Tomé e Príncipe e Fiji foram excluídos da amostra, uma vez que o primeiro não possuía informações relativas ao nível de democracia e o segundo não apresentava informações relacionadas ao nível corrupção.

$7 \quad$ O Open Budget Index é uma pesquisa independente, realizada, bianualmente, pelo Open Budget Partnership e que tem por objetivo construir uma medida comparativa e regular da transparência orçamentária de da accountability em todo o mundo.
Quanto as variáveis utilizadas no estudo, o Quadro 1 apresenta as variáveis utilizadas, seus significados, a fonte de dados utilizada e os sinais esperados de cada variável. Além disso, apresenta-se, em seguida, de forma resumida, a sustentação teórica de cada variável.

Quadro 1. Variáveis utilizadas no estudo

\begin{tabular}{|c|c|c|c|}
\hline VARIÁVEL & $\begin{array}{c}\text { NOTAÇÃO } \\
\text { UTILIZADA }\end{array}$ & FONTE & $\begin{array}{c}\text { SINAL } \\
\text { ESPERADO }\end{array}$ \\
\hline Transparência & Transp & OBI Index 2010 & \\
\hline $\begin{array}{c}\text { Nível de } \\
\text { democracia }\end{array}$ & demlevel & $\begin{array}{c}\text { Economist } \\
\text { Inteligent Unit's } \\
\text { Index 2010 }\end{array}$ & Positivo \\
\hline Riqueza & wealth & Índex-mund & Positivo \\
\hline $\begin{array}{c}\text { Poder do } \\
\text { legislativo }\end{array}$ & legpower & OBI Index 2010 & Positivo \\
\hline $\begin{array}{c}\text { Poder dos } \\
\text { SAIs }\end{array}$ & SAIpower & $\begin{array}{c}\text { OBI índex 2010 } \\
\text { Economist } \\
\text { Inteligent Unit's } \\
\text { Index 2010 }\end{array}$ & Positivo \\
\hline $\begin{array}{c}\text { Accountability } \\
\text { account }\end{array}$ & $\begin{array}{c}\text { Transparência } \\
\text { Internacional }\end{array}$ & Positivo* \\
\hline Corrupção & corrup & \multicolumn{2}{|c|}{} \\
\hline
\end{tabular}

*Espera-se que a relação seja positiva, pois as escalas são inversamente proporcionais.

Identificação e justificativa das variáveis:

- $\quad$ Nível de democracia (demlevel): relatório do OBP (2010) indica que países onde a democracia está mais consolidada possuem maiores índices de transparência.

- $\quad$ Riqueza (PIB/capta) (wealth): estudo de Alt, Lassen e Rose (2006) aponta que países mais ricos tendem a ser mais transparentes.

- Poder do legislativo (legpower): Poder que o legislativo de um país possui para aprovar orçamentos no início do ano e para aprovar todas as emendas feitas durante o ano fiscal. Além disso, considera, também, o tempo que o legislativo tem para avaliar o orçamento e a abertura das discussões sobre o mesmo. Estudo de Kaufman (2005) aponta que poderes legislativos mais independentes melhoram a transparência fiscal.

- Poder dos SAI (SAIpower): Mensura o nível de independência dos SAIs do executivo, tais como: procedimentos para destituir o chefe do Instituto, nível de autorização legal para os SAIs auditarem o que desejarem, etc. Kaufman (2005) aponta que SAIs com maior nível de independência do Executivo melhoram a transparência fiscal.

- Accountability (account): nível de accountability. Estudo de Maijer (2009) e Florini (2007) indicam que a transparência melhora a accountability dos países.

- Corrupção (corrup): percepção de corrupção dos países. Estudos teórico de Meijer (2009); Relyea (2009) e Florini (2007) indicam que a transparência e os mecanismos de responsabilização reduzem a 
corrupção e aumenta o nível de democracia.

Para testar as hipóteses utilizou-se o método dos mínimos quadrados ordinários (MQO), sendo que os testes foram realizados em etapas, para cada hipótese.

$\mathrm{Na}$ primeira hipótese, foi testada a efetividade dos institutos supremos de auditoria na transparência fiscal dos países e o modelo utilizado é o apresentado na Equação 1.

$$
\text { Transp }=\alpha+\beta_{1 \text { legpower }}+\beta_{2 \text { SAlpower }}+\beta_{6 \text { wealth }}+e_{i}
$$

Com a finalidade de comprovar empiricamente a teoria, que estabelece que a transparência melhora a accountability e por consequência aumenta o nível de democracia e reduz a corrupção, foram testados três modelos. O primeiro busca identificar se, de fato, maior transparência resulta em mais mecanismos de accountability e consequentemente, maior responsabilização. Esse modelo pode ser visualizado na Equação 2.

$$
\text { Account }=\alpha+\beta_{\text {ltransp }}+\beta_{2 \text { wealth }}+e_{i}
$$

O segundo modelo teve por finalidade identificar se maior transparência e mais mecanismos de accountability melhoram, de fato, o nível de democracia dos países. O modelo pode ser visto na Equação 3.

$$
\text { Democ }=\alpha+\beta_{1 \text { transp }}+\beta_{2} \mathrm{a}_{\text {ccount }}+\beta_{3 \text { wealth }}+e_{i}
$$

Por fim, o terceiro modelo objetivou identificar se, de fato, mais transparência e maior accountability resulta em menores índices de corrupção. Esse modelo é apresentado na Equação 4.

$$
\text { Corrup }=\alpha+\beta_{1 \text { transp }}+\beta_{\text {2account }}+\beta_{3 \text { wealth }}+e_{i}
$$

Em todos os modelos a variável riqueza per capta (wealth) foi utilizada como variável de controle, uma vez que países com melhores condições econômicas podem dispor de maiores mecanismos informacionais não necessariamente por causa do seu nível de democracia ou corrupção. Para realizar os testes apresentados utilizouse o software Eviews 6.0 e os níveis de significância para todos os testes foi de $0,05(5 \%)$.

\section{APRESENTAÇÃO E ANALISE DOS RESULTADOS}

Essa seção apresenta os resultados deste trabalho e divide-se em quatro partes. A primeira busca identificar a relação entre a independência dos Institutos Supremos de Auditoria e dos Poderes Legislativos no nível de transparência dos países. A segunda busca identificar a relação existente entre transparência e mecanismos de accountability dos países. A terceira parte procura identificar a relação existente entre transparência e accountability no nível de democracia dos países da amostra; ao passo que a quarta parte busca estabelecer a associação das variáveis transparência e accountability no nível de democracia dos países que integram a amostra.

\subsection{Poder das SAIs e Independência dos Poderes Legislativos}

Conforme descrito anteriormente, o primeiro teste realizado neste trabalho consistiu em identificar a efetividade dos Institutos Supremos de Auditoria na transparência fiscal dos países e, o modelo utilizado foi o apresentado na Equação 1. A variável PIB/capta foi utilizada como variável de controle.

Os resultados apresentados na Tabela 1 evidenciam que as variáveis relacionadas à efetividade dos Institutos Supremos de Auditoria e dos Poderes Legislativos (Equação 1) apresentaram-se significativas ao nível de significância de $5 \%$. Acrescenta-se, ainda, que o modelo apresentou $\mathrm{R}^{2}$ ajustado de $0,5827(58 \%)$ e que a constante não se apresentou estatisticamente significativa. Destacase, adicionalmente, que também houve preocupação em controlar o modelo por variáveis dummy de região (Leste da Ásia e Pacífico, Europa Oriental e Ásia Central, América Latina e Caribe, Meio Leste e Norte da África, Sul da Ásia, África Subsaariana). Todavia, as mesmas não se mostraram significativas nos modelos apresentados e, algumas vezes, mesmo que tivessem significância estatística não faziam sentido nos modelos testados.

Tabela 1. Resultado da Regressão - Equação 1

\begin{tabular}{ccccc}
\hline Variable & Coefficient & Std. Error & t-Statistic & Prob. \\
\hline $\begin{array}{c}\text { Independência } \\
\text { do Poder } \\
\text { Legislativo }\end{array}$ & 0,261547 & 0,113030 & 2,313953 & 0.0489 \\
\hline Poder das SAIs & 0,508204 & 0,096519 & 5,265479 & 0,0000 \\
\hline PIB/capta & 0,000303 & 0,000166 & 1,822520 & 0,0718 \\
\hline Constante & 3,018251 & 4,537539 & 0,665175 & 0,5077 \\
\hline
\end{tabular}

Nível de significância de 5\%

No que se refere aos pressupostos da regressão apresentada, pode-se verificar, na Tabela 2, que os mesmos foram atendidos e, desta forma, pode-se constatar a efetividade da teoria ao afirmar que instituições democráticas e orçamentárias dotadas de maiores poderes constitucionais aumentam a transparência fiscal dos países. 
Tabela 2. Testes dos Pressupostos da Regressão - Equação 1

\begin{tabular}{c|c|c|c}
\hline PRESSUPOSTO & TESTE & $\boldsymbol{\alpha}$ UTILIZADA & ENCONTRADA \\
\hline Normalidade & Jarque-Bera & 0,05 & 0,3155 \\
\hline \multirow{2}{*}{$\begin{array}{c}\text { Autocorre } \\
\text { lação }\end{array}$} & $\begin{array}{c}\text { Breush- } \\
\text { Godfrey (LM } \\
\text { test) }\end{array}$ & 0,05 & 0,3743 \\
\cline { 2 - 4 } & $\begin{array}{c}\text { Durbin- } \\
\text { Watson }\end{array}$ & Não utilizado & 1,9387 \\
\hline $\begin{array}{c}\text { Homoceda } \\
\text { sticidade }\end{array}$ & White & 0,05 & $0,0467^{1}$ \\
\hline \multirow{2}{*}{$\begin{array}{c}\text { Não } \\
\text { colinearidade } \\
\text { perfeita }\end{array}$} & $\begin{array}{c}\text { Fator de } \\
\text { inflação } \\
\text { variância } \\
\text { (FIV) }\end{array}$ & $>10$ & 2,47 \\
\cline { 2 - 4 } & Tolerância & $>0,05$ & 0.4035 \\
\hline
\end{tabular}

${ }^{1}$ Para corrigir o problema de heteroscedasticidade foi aplicada a correção de White e a análise se deu com os erros padrões robustos.

\subsection{A influência da transparência nos mecanismos de accountability}

Nessa etapa do trabalho foi testado se, de acordo com a teoria, países com maior indicadores de transparência apresentam mais mecanismos de accountability. Acreditase que, pelo fato de existirem maiores informações disponíveis, existirá maior monitoramento social e, por consequência, maior responsabilização.

Ao se efetuar os cálculos da Equação 2, a variável transparência (transp) apresentou-se significativa ao nível de significância de $5 \%$ (sig. 0,0008$)$ e com $\mathrm{R}^{2}$ de $22 \%$, evidenciando o que atesta a teoria, ou seja, que países com maior nível de transparência possuem mais mecanismos de responsabilização. Destaca-se que a constante não se mostrou significativa. Adicionalmente, os pressupostos da regressão também foram testados e os resultados encontrados podem ser visualizados na Tabela 3.

Tabela 3. Testes Dos Pressupostos Da Regressão - Equação 2

\begin{tabular}{|c|c|c|c|}
\hline Pressuposto & Teste & $\begin{array}{c}\text { Sig. } \\
\text { Utilizada }\end{array}$ & $\begin{array}{c}\text { Sig. } \\
\text { Encontrada }\end{array}$ \\
\hline Normalidade & $\begin{array}{c}\text { Jarque- } \\
\text { Bera }\end{array}$ & 0,05 & 0,1301 \\
\hline \multirow[t]{2}{*}{ Autocorrelação } & $\begin{array}{l}\text { Breush- } \\
\text { Godfrey } \\
\text { (LM test) }\end{array}$ & 0,05 & 0,7461 \\
\hline & $\begin{array}{l}\text { Durbin- } \\
\text { Watson }\end{array}$ & $\begin{array}{c}\text { Não } \\
\text { utilizado }\end{array}$ & 1,8625 \\
\hline $\begin{array}{l}\text { Homocedas } \\
\text { ticidade }\end{array}$ & White & 0,05 & 0,2224 \\
\hline \multirow[t]{2}{*}{$\begin{array}{l}\text { Não colinearidade } \\
\text { perfeita }\end{array}$} & $\begin{array}{c}\text { Fator de } \\
\text { inflação } \\
\text { variância } \\
\text { (FIV) }\end{array}$ & $<10$ & 1,29 \\
\hline & Tolerância & $>0,05$ & 0,7751 \\
\hline
\end{tabular}

Desta forma, dado que os pressupostos da regressão foram atendidos e que não há erros de especificação do modelo, pode se inferir que mais transparência aumenta o controle social e, consequentemente, resulta em mais mecanismos de responsabilização dos gestores.

\subsection{Influência da transparência e da accountability na democracia dos países}

Com o objetivo de, mais uma vez, verificar a efetividade da teoria, que menciona que mais transparência e accountability melhoram o nível de democracia dos países, efetuou-se os testes constantes da Equação 3 e os resultados podem ser visualizados na Tabela 4.

Tabela 4. Resultado Da Regressão - Equação 3

\begin{tabular}{ccccc}
\hline Variable & Coefficient & Std. Error & t-Statistic & Prob. \\
\hline $\begin{array}{c}\text { Nível de } \\
\text { Transparência }\end{array}$ & 0.050752 & 0,006942 & 7,310891 & 0,0000 \\
\hline Accountability & 0,004801 & 0,002826 & 1.699270 & 0,0928 \\
\hline PIB/capta & $3,10 \mathrm{E}-05$ & $1,37 \mathrm{E}-05$ & 2,263034 & 0,0261 \\
\hline Constante & 2,953560 & 0,276683 & 10,67487 & 0,0000 \\
\hline
\end{tabular}

Conforme se observa na Tabela 4, a variável transparência apresentou-se significativa a $5 \%$, ao passo que a variável accountability apresentou-se significativa apenas ao nível de $10 \%$. Nesse sentido, pode-se afirmar que tanto a transparência melhora a accountability como elas em conjunto melhoram o nível de democracia de um país, uma vez que maior e melhor nível informacional resulta e maior responsabilização (política ou legal) e, consequentemente, maior poder do povo em escolher e punir o gestor.

Destaca-se, que o modelo apresentou $\mathrm{R}^{2}$ de $66 \%$, evidenciando que grande parte da variação no nível de democracia dos países estudados é explicada pela transparência e pela accountability, em conjunto.

Para que um modelo possa ser usado para se fazer inferências, é necessário que os pressupostos da regressão linear sejam atendidos. Assim, buscando comprovar a efetividade do modelo e o atendimento dos pressupostos da regressão, foram efetuados os testes dos mesmos, que são apresentados na Tabela 5.

Tabela 5. Testes Dos Pressupostos Da Regressão - Equação 3

\begin{tabular}{|c|c|c|c|}
\hline Pressuposto & Teste & $\begin{array}{c}\text { Sig. } \\
\text { Utilizada }\end{array}$ & $\begin{array}{c}\text { Sig. } \\
\text { Encontrada }\end{array}$ \\
\hline Normalidade & Jarque-Bera & 0,05 & 0,6162 \\
\hline \multirow{2}{*}{$\begin{array}{l}\text { Autocorre } \\
\text { lação }\end{array}$} & $\begin{array}{c}\text { Breush- } \\
\text { Godfrey (LM } \\
\text { test) }\end{array}$ & 0,05 & 0,4702 \\
\hline & $\begin{array}{l}\text { Durbin- } \\
\text { Watson }\end{array}$ & $\begin{array}{c}\text { Não } \\
\text { utilizado }\end{array}$ & 1,9927 \\
\hline $\begin{array}{l}\text { Homocedas } \\
\text { ticidade }\end{array}$ & White & 0,05 & $0,051^{2}$ \\
\hline \multirow{2}{*}{$\begin{array}{c}\text { Não } \\
\text { colinearidade } \\
\text { perfeita }\end{array}$} & $\begin{array}{c}\text { Fator de } \\
\text { inflação } \\
\text { variância } \\
\text { (FIV) }\end{array}$ & $>10$ & 3,00 \\
\hline & Tolerância & $>0,05$ & 0,3323 \\
\hline
\end{tabular}

${ }^{2}$ Para corrigir o problema de heteroscedasticidade foi aplicada a correção de White e a análise se deu com os 
erros padrões robustos.

Uma vez que todos os pressupostos foram atendidos, pode-se inferir, a partir das Equações 2 e 3, que a transparência aumenta a accountability e ambas, em conjunto, melhoram o nível de democracia dos países. Nesse sentido, pode-se afirmar que a transparência é fator primordial para a consolidação da accountability dos países e, por isso, deve ser exigida pela população.

\subsection{Influência da transparência e da accountability no nível de corrupção dos países}

Por fim, buscando identificar a relevância da transparência e da accountability no nível de corrupção dos países realizou-se os cálculos relativos a Equação 4, cujos coeficientes, níveis de significância e probabilidades podem ser visualizados na Tabela 6 .

Tabela 6. Resultado Da Regressão - Equação 4

\begin{tabular}{ccccc}
\hline Variable & Coefficient & Std. Error & t-Statistic & Prob. \\
\hline $\begin{array}{c}\text { Nível de } \\
\text { Transparência }\end{array}$ & 0,023048 & 0,006743 & 3,417898 & 0,0010 \\
\hline Accountability & 0,003080 & 0,002398 & 1.284747 & 0,2023 \\
\hline PIB/capta & 8.639102 & 1.512260 & 5.712709 & 0,0000 \\
\hline Constante & 1,559865 & 0,233530 & 6,679500 & 0,0000
\end{tabular}

Conforme se observa na Tabela 6 , as variáveis transparência, PIB/capta (riqueza) e a constante apresentaram-se significativa no modelo testado. A variável accountability não se mostrou significativa. Como o $\mathrm{R}^{2}$ da regressão foi de $67,92 \%$, pode-se inferir que, de fato, a transparência reduz a corrupção, uma vez que mais informações geram maior pressão social e a exigência de instituições democráticas eficientes.

Os pressupostos desse modelo foram testados buscando atestar a efetividade do mesmo e, desta forma, fazermos inferências. Como o modelo fora aprovado em todos os pressupostos pode-se utilizá-lo para fazer inferências sobre a transparência dos países, sendo que os resultados podem ser vistos na Tabela 7 .

Tabela 7. Testes Dos Pressupostos Da Regressão - Equação 4

\begin{tabular}{cccc}
\hline Pressuposto & Teste & $\begin{array}{c}\text { Sig. } \\
\text { Utilizada }\end{array}$ & $\begin{array}{c}\text { Sig. } \\
\text { Encontrada }\end{array}$ \\
\hline Normalidade & $\begin{array}{c}\text { Jarque-Bera } \\
\text { Breush- }\end{array}$ & 0,05 & 0,0870 \\
\hline Autocorrelação & $\begin{array}{c}\text { Godfrey } \\
\text { (LM test) }\end{array}$ & 0,05 & 0,1130 \\
$\begin{array}{c}\text { Durbin- } \\
\text { Watson }\end{array}$ & $\begin{array}{c}\text { Não } \\
\text { utilizado }\end{array}$ & 2,3501 \\
\hline $\begin{array}{c}\text { Homoce } \\
\text { dasticidade }\end{array}$ & White & 0,05 & $0,0132^{3}$ \\
\hline $\begin{array}{c}\text { Fator de } \\
\text { inflação } \\
\text { colinearidade } \\
\text { perfeita }\end{array}$ & $\begin{array}{c}\text { variância } \\
\text { (FIV) }\end{array}$ & $>10$ & 3,1172 \\
\cline { 2 - 4 } Tolerância & $>0,05$ & 0,3208 \\
\hline
\end{tabular}

${ }_{3}^{3}$ Para corrigir o problema de heteroscedasticidade foi aplicada a correção de White e a análise se deu com os erros padrões robustos.

De acordo com os modelos anteriormente apresentados, pode-se inferir que países onde o processo orçamentário ocorre sobre a supervisão de instituições supremas de auditoria e poderes legislativos independentes e com poderes definidos constitucionalmente apresentam maior transparência fiscal, evidenciando a relevância dessas instituições na transparência fiscal dos países.

Adicionalmente, verificou-se que países com maior transparência possuem mais mecanismos de accountability e que tanto a transparência como a accountability estão fortemente associadas ao nível de democracia. Por fim, verificou-se que a transparência reduz a corrupção, indicando a relevância da mesma no processo democrático, econômico e financeiro dos países.

\section{CONSIDERAÇÕES FINAIS}

Esse trabalho buscou identificar a efetividade dos Institutos Supremos de Auditoria e dos Poderes Legislativos na transparência fiscal (orçamentária) dos países constantes do Open Budget Index 2010 e, adicionalmente, verificar a efetividade da teoria, que afirma que maior transparência melhora a democracia e reduz a corrupção.

Verificou-se que, de fato, países com Instituições Supremas de Auditoria com maior independência e maior poder, constitucionalmente definido, apresentam maior transparência, uma vez que essas instituições, por deterem maior poder e independência do executivo, irão agir a partir de interesses distintos dos do executivo, reduzindo, dessa forma, os conflitos de interesses entre os governantes e os governados.

Além disso, constatou-se, também, que nos países onde os poderes legislativos possuem processos orçamentários independentes, com poderes para aprovar, vetar e emendar os orçamentos, a transparência foi maior, evidenciando que tanto individualmente, quanto conjuntamente, a independência dos poderes legislativos e das SAIs, contribuem para um processo orçamentário mais transparente, permitindo ao público monitorar e, consequentemente, cobrar responsabilização ou premiar os gestores públicos por meio da manutenção destes nos cargos eletivos.

No que se refere aos mecanismos de accountability identificou-se que os mesmos estão associados à maior transparência, todavia, com baixa representatividade. Não é de se estranhar tal achado, uma vez que mais mecanismos de accountability não implicarão em maior transparência e, a existência dessa última possibilitará mais mecanismos de accountability se as instituições democráticas dos países forem eficientes. Além disso, a responsabilização pode ocorrer no processo eleitoral, uma vez que os eleitores poderão punir o gestor público não o reelegendo para um novo mandato. Apesar de essa ultima hipótese não ter sido testada nesse trabalho, evidenciase que a existência de informação acerca da conduta do gestor frente aos negócios públicos influencia no processo de definição do voto. A percepção da corrupção, quando assume dimensão pública, pode interromper carreiras políticas antes tidas como promissoras. 
Constatou-se, ainda, de acordo com a teoria, que quando a transparência aumenta, leva consigo a democracia e, como resultado da maior transparência e de maior democracia, há a redução da corrupção. Dessa forma, além de constatar a efetividade das teorias, constatou-se, também a efetividade dos papéis a serem desempenhados pelos Poderes Legislativos e pelas Instituições Supremas de Auditoria no processo de transparência, evidenciando a importância da transparência no processo de consolidação democrática, uma vez que permite ao cidadão conhecer as informações relevantes para punir ou premiar os gestores e, além disso, exigir das instituições existentes maior eficiência na punição dos gestores quanto a malversação de recursos públicos. Como consequência, a transparência leva a maior democracia e menos corrupção.

Nesse sentido, a responsabilidade do cidadão no processo eleitoral se torna cada vez mais importante, uma vez que ao se eleger bons representantes para o parlamento, tem-se a possibilidade de um legislativo mais consistente e independente. Além disso, para a consolidação da transparência, da accountability e redução da corrupção, torna-se primordial a participação do povo no processo político e informacional. Para que essa participação se efetive, o povo deve possuir capacidade analítica e critica sobre o processo políticogerencial para que possa punir os gestores alicerçados por boas informações.

Por fim, sugere-se para futuras pesquisas, investigar se países com maior transparência possuem custos de captação de recursos financeiros mais justos do que países menos transparentes; verificar como a divulgação de déficits e superávits influenciam os resultados das eleições e; como a relação contratual entre estados e organismos internacionais influencia a transparência orçamentária.

\section{REFERÊNCIAS BIBLIOGRAFICAS}

ALT, J.E. LASSEN, D.D.ROSE, S. The Causes of Fiscal Transparency: Evidence from the U.S. states. IMF Staff Papers n. 53, Special Issue p. 30-57, 2006.

BALL, C. What is transparency? Public Integrity, v. 11, n. 4, p. 293-308, Fall, 2009.

BERNOTH, K., WOLFF, G. B. Fool the markets? Creative accounting, fiscal transparency and sovereign risk premia. Scottish Journal of Political Economy. v. 55, n. 4, p. 465-487, 2008.

BERTOT, J. C.; McClURE, C. R.; WRIGHT, C. B.; JANSEN, E.; THOMAS, S. Public libraries and internet 2009: study, results and findings. Disponível em: $<\underline{\text { http://ii.fsu.edu/Solutions/Public- }}$ Libraries-The-Internet $>$. Acesso em 30/03/2012.

BESSETTE, J. M. Accountability: Political. In:
SMELSER, N. J.; BALTES, P. B.(Org.) International Encyclopedia of the Social \&Behavioral Sciences. Oxford, U.K.: Elsevier, 2001. p. 38-41.

BIRKINSHAW, P.J. Freedom of information and openness: Fundamental human rights. Administrative Law Review, v. 58, n.1, p. 177-218, 2006.

CAMPOS, Anna Maria. Accountability: quando poderemos traduzi-la para o português?

Revista de Administração Pública, Rio de Janeiro, fev./ abr. 1990.

COGLIANESE, C. The Transparency President? The Obama Administration and Open Government. Governance, v. 22, p. 529-544, Oct. 2009.

COLECCHIA, A. SCHREYER, P. The Contribution of Information and Communication Technologies to Economic Growth in Nine OECD Countries. OECD Economic Studies v.34, p.153-171, 2002.

CORREA,I.M.;SPINELLI,M.V.C.TransparencyPolicies in Brazilian Public Administration. Revista Del Clad Reforma y Democracia. N. 51, p. 129-140, Oct. 2011.

CUILLIER, D.; PIOTROWSKI, S. Internet informationseeking and its relation to support for access to government records. Government Information Quarterly. v 26, n. 3, p. 441-449, Jul. 2009.

CHANDY, L. e KHARAS, H. Why Can't We All Just Get Along? The Practical Limits to International Development. Journal of International Development. v.23, n. 5, p. 739-751, Jul. 2011.

FLORINI, A. The right to know : transparency for an open world. New York. Columbia University Press, 2007.

FOX, J. Government transparency and policymaking. Public Choice, v. 131, n. 1, p. 23 - 44, Apr. 2007.

GRIGORESCU, A. International organizations and Government Transparency: Linking the International and Domestic Realms. International Studies Quarterly. V. 47, n. 4, p. 643-667, Dec. 2003.

HAGEN, J. V. Budgeting Institutions for Better Fiscal Performance. In: Budgeting and Budgetary Institutions. Anwar Shan. Washington: The World Bank, 2007.

HALLERBERG, M.; WOLFF, G. B. Fiscal institutions, fiscal policy and sovereign risk premia in EMU. Public Choice, v. 136, n. 3-4, p. 379-396, Mar. 2008. 
HALL, P.A. e TAYLOR, R. C. R. The three versions of neo-institutionalism. Lua Nova, v. p. 58:193-223, 2003.

HEALD, D. "Fiscal Transparency: Concepts, Measurement and UK Practice." Public Administration. v. 81, n. 4, p. 723-759, Dec. 2003.

HEPPKE-FALK, K.; WOLFF, G. B. Moral hazard and bail-out in fiscal federations: evidence for the german länder. Kyklos, v. 61, n. 3, P. 425-446, Jul. 2008 .

HOLZNER, B.; HOLZNER, L. Transparency in Global Change: The Vanguard of the Open Society. Pittsburgh, PA: University of Pittsburgh Press, 2006.

HOOD C. Transparency in historical perspective. In: Hood C. and Heald D. (eds) Transparency: The Key to Better Governance? New York: Oxford University Press, p. 3-23, 2006.

IBP - International Budget Partnership. Open Budget Survey 2010. Disponível em: <http:// internationalbudget.org/what-we-do/open-budgetsurvey/>. Acesso em set. 2011.

KAUFMAN, D. Special Report, Transparency Matters: The 'Second Generation' of Institutional Reform, (2005), The World Bank. Disponível em:

http://topics,developmentgateway.org/special/ transparency/template2.do. Acesso em $22 \mathrm{dec}$. 2011.

KOPITS, G.; CRAIG, J. Transparency in government operations. Occasional Paper 158. International Monetary Fund. Washington DC: 1998.

KRASNER, S. D. International Regimes. Cornell: Cornell University Press, 1983.

LORD, B.R. Accounting for Total Quality Management. $\mathrm{PhD}$, University of Waikato, Hamilton, New Zealand, 2000

LOUREIRO, M. R. ; BRAGA, A. C. ; FARAH, M. ; AZEVEDO, C. B. ; BRESLER, R. Novos Desafios para cursos nas áreas públicas. Temas de Administração Pública (UNESP. Araraquara), v. 1, p. 1-15, 2010.

MATTIAS PEREIRA, J. "Reforma do Estado e transparência: estratégias de controle da corrupção no Brasil. In: VII Congreso Internacional del CLAD sobre la Reforma del Estado y de la Administración Pública, Lisboa, Portugal, 8-11 Oct. 2002.

MEIJER, A, Understaning Modern Transparency. International Review of Administrative Science, v.
75, n. 2, p. 255-269, Jun. 2009.

MULGAN, R. Truth in Government and the Politicization of Public Service Advice. Public administration, $v$. 85, n. 3. P. 569-583, set. 2007.

O'NEILL, O. Transparency and the ethics of communication. In: HOOD, C. and HEALD, D. (eds) Transparency: The Key to Better Governance? New York: Oxford University Press, p. 75-90, 2006.

OLIVER, R.W. What is Transparency? New York: McGraw-Hill, 2004.

PALLAS, C.L.; URPELAINEN, J. NGO monitoring and the legitimacy of international cooperation: A strategic analysis. Review of International Organizations.v. 7, n. 1, p. 1-32, Mar 2012.

PARK, H., BLENKINSOPP, J. The roles of transparency and trust in the relationship between corruption and citizen satisfaction. International Review of Administrative Sciences. v. 77, n, 2, p. 254-274, 2011.

PASQUIER, M.; VILLENEUVE J. P. Organizational barriers to transparency: A typology and analysis of organizational behaviour tending to prevent or restrict access to information. International Review of Administrative Sciences, v. 73, n. 1, p. 147-162, Mar. 2007.

PHILIPPS, L.; STEWART. Defining Fiscal Transparency: Transnational Norms, Domestic Laws and the Politics of Budget Accountability. Law Research Paper Series, v. 4, n. 7, 2008.

PINHO, J. A. G; SACRAMENTO, A. R. S.

Accountability: já podemos traduzi-la para o

português? Revista de Administração Pública, Rio de Janeiro, n43, p.1343-1368,

nov/dez.2009.

PIOTROWSKI, S. J. Governmental Transparency in the Path of Administrative Reform. Albany, NY: State University of New York Press. 2007.

PRADO, O; RIBEIRO M. M; DINIZ, E. Governo eletrônico e transparência: olhar crítico sobre os portais do governo federal brasileiro. In PINHO, José Antonio Gomes (org.) Estado, sociedade e interações digitais: expectativas democráticas. Editora EDUFBA, Salvador, 2012.

PRZEWORSKI, A. Democracy and the Limits of SelfGovernment. New York: Cambridge University Press, 2010.

RELYEA, H. C. Federal freedom of information policy: 
Highlights of recent developments. Government Information Quarterly, v. 26, n. 2, p. 314-320. Abril 2009.

RIBEIRO, Renato Janine. A sociedade contra o social: o alto custo da vida pública no Brasil. São Paulo, Companhia das Letras, 2000.

SANTISO, C. Legislatures and Budget Oversight in Latin America: Strengthening Public Finance Accountability in Emerging Economies. OECD Journal on Budgeting, v. 4, n. 2. OECD, 2004.

SARTORI, G. A teoria da democracia revisitada. São Paulo: Editora Ática, 1994.

SCHEDLER, Andreas. Conceptualizing accountability. In: SCHEDLER, A.; DIAMOND, L.; PLATTNER, M. F. (Eds.). The self-restraing state. Power and accountability in new democracies. Boulder and London: Lynne Rienner Publishers, 1999.

SHULER, J. A.; JAEGER, P. T.; BERTOT, J. C. Implications of harmonizing e-government principles and the Federal Depository Library Program (FDLP). Government Information Quarterly, v. 27, p. 9-16. 2010.

SILVA, M. F. G. A economia política da corrupção, São Paulo: Transparência Brasil, 2001.

SPECK, B. (org,). Caminhos da Transparência. Editora da UNICAMP. Campinas, .2002

TEIXEIRA, M. A. C. TRIBUNAL DE CONTAS DA UNIÃO: Trajetória Institucional e Desafios Contemporâneos. In: Alexandre dos Santos Cunha; Bernardo de Abreu Medeiros; Luseni Maria Aquino. (Org.). Estado, Instituições e Democracia: república. 1 ed. Brasília: IPEA, 2010.

THOMPSON, John B. O escândalo político: poder e visibilidade na era da mídia. Petrópolis: Editora Vozes, 2002.

WEST, D.M. E-government and the Transformation of Service Delivery and Citizen Attitudes. Public Administration Review, v. 64, n. 1, p. 15-27, Mai 2004 
ANEXOS

Quadro 2. RELAÇÃO DOS PAÍSES CONSTANTES DA AMOSTRA

\begin{tabular}{|l|l|l|l|l|l|}
\hline N. & PAÍS & N. & PAÍS & N. & PAÍS \\
\hline 1 & AFEGANISTÃO & 32 & ESPANHA & 63 & NORUEGA \\
\hline 2 & ÁFRICA DO SUL & 33 & ESTADOS UNIDOS & 64 & NOVA ZELÂNDIA \\
\hline 3 & ALBÂNIA & 34 & FILIPINAS & 65 & PAPUA NOVA GUINÉ \\
\hline 4 & ALEMANHA & 35 & FRANÇA & 66 & PAQUISTÃO \\
\hline 5 & ANGOLA & 36 & GANA & 67 & PERU \\
\hline 6 & ARÁBIA SAUDITA & 37 & GEÓRGIA & 68 & POLÔNIA \\
\hline 7 & ARGÉLIA & 38 & GUATEMALA & 69 & PORTUGAL \\
\hline 8 & ARGENTINA & 39 & GUINÉ EQUATORIAL & 70 & REINO UNIDO \\
\hline 9 & AZERBAIJ̃̃O & 40 & HONDURAS & 71 & REP. DEM. CONGO \\
\hline 10 & BANGLADESH & 41 & IÊMEN & 72 & REP. QUIRGUISTÃO \\
\hline 11 & BOLÍVIA & 42 & INDIA & 73 & REP. DOMINICANA \\
\hline 12 & BÓSNIA E HERZEGOVINA & 43 & INDONÉSIA & 74 & REPÚBLICA THECA \\
\hline 13 & BOTSUANA & 44 & IRAQUE & 75 & ROMÊNIA \\
\hline 14 & BRASIL & 45 & ITÁLIA & 76 & RUANDA \\
\hline 15 & BULGÁRIA & 46 & JORDÂNIA & 77 & RUSSIA \\
\hline 16 & BURKINA FASO & 47 & KÊNIA & 78 & SENEGAL \\
\hline 17 & CAMARÕES & 48 & LÍBANO & 79 & SÉRVIA \\
\hline 18 & CAMBOJA & 49 & LIBÉRIA & 80 & SRI LANKA \\
\hline 19 & CAZAQUISTÃO & 50 & MACEDÔNIA & 81 & SUDÃO \\
\hline 20 & CHADE & 51 & MALÁSIA & 82 & SUÉCIA \\
\hline 21 & CHILE & 52 & MALAWI & 83 & TAILÂNDIA \\
\hline 22 & CHINA & 53 & MALI & 84 & TANZÂNIA \\
\hline 23 & COLÔMBIA & 54 & MARROCOS & 85 & TIMOR LESTE \\
\hline 24 & CORÉIA DO SUL & 55 & MÉXICO & 86 & TRINIDAD Y TOBAGO \\
\hline 25 & COSTA RICA & 56 & MOÇAMBIQUE & 87 & TURQUIA \\
\hline 26 & CROÁCIA & 57 & MONGÓLIA & 88 & UCRÂNIA \\
\hline 27 & EGITO & 59 & NEPAL & 89 & UGANDA \\
\hline 28 & EL SALVADOR & 90 & VENEZUELA \\
\hline 29 & EQUADOR & 61 & NÍGER & 92 & ZIETNÃ \\
\hline 30 & ESLOVÁQUIA & 62 & NIGÉRIA & & \\
\hline 31 & ESLOVÊNIA & & & & \\
\hline & & AAGIA \\
\hline
\end{tabular}

Este artigo originalmente foi publicado em inglês pela International Business Research; "Budgetary Transparency and Democracy: The Effectiveness of Control Institutions" Vol. 7, No. 6; 2014 - URL: http://dx.doi.org/10.5539/ibr.v7n6p83 Reproduzido em língua portuguesa com a autorização da Canadian Center of Science and Education. 